\title{
Renal Function Status in the Newborn with Perinatal Asphyxia
}

\author{
Tarun Kumar Roy ${ }^{* 1}$, Mahmood A Chowdhury Arzu², Wazir Ahmed ${ }^{3}$, Didarul Alam ${ }^{4}$, \\ Sanjana Islam ${ }^{5}$, Rabeya Sultana ${ }^{6}$, Suvendu Ray ${ }^{7}$
}

\section{Abstract}

Introduction: Renal involvement is frequent in neonates with perinatal asphyxia. It is correlated with the severity of neurological damage and degree of involvement depends upon the severity of asphyxia. To assess the status of renal function in new born suffering from prenatal asphyxia and to precise the relationship between severity cerebral damage and renal failure. Materials and Methods: A hospital based cross-sectional study was conducted in the department of Neonatology, Chattogram Maa O Shishu Medical College Hospital, Agrabad, Chattogram on 180 full-term neonates (150 cases and 30 control). The cases were categorized according to HIE Sarnat stages. Results: Among cases, 83(53.4\%) were with HIE I, $53(35.3 \%)$ were HIE II and 14(9.3\%) were HIE III. The mean value of S. Creatinine was high in cases $1.64 \pm$ $0.33 \mathrm{mg} / \mathrm{dl}$ vs $0.41 \pm 0.09 \mathrm{mg} / \mathrm{dl}$ ( $p$ value $<0.001)$ and it is highest in HIE stage III $1.85 \pm 0.20 \mathrm{mg} / \mathrm{dl}(\mathrm{p}$ value is $<0.001)$. Mean Serum Potassium was high in cases $5.88 \pm 0.59 \mathrm{mmol} / \mathrm{L}$ vs $3.99 \pm 0.36$ ( $p$ value $<0.001$ ) and the values are abnormally high in HIE stage III $6.25 \pm 0.33$ ( $p$ value $<0.001$ ). The mean value of FeNa was high in cases $2.44 \pm 0.55$ compared with control $1.06 \pm 0.38$ ( $p$ value $<0.001)$ and it is higher in HIE stage III $2.72 \pm 0.22(p$ value is $<0.001)$. Conclusion: Severity of renal impairment correlates well with the degree of HIE. HIE stage wise assessment of renal function status using serum creatinine level, S. potassium, FeNa, can be used to assess the outcome of perinatal asphyxia.

Keywords: Perinatal asphyxia, Hypoxic ischemic encephalopathy, Acute kidney injury.

Number of Tables: 05; Number of References: 10; Number of Correspondence: 04.

*1. Corresponding Author:

Dr. Tarun Kumar Roy, MD (Paediatrics)

Assistant Professor, Department of Paediatrics Bangabandhu Memorial Hospital

University of Science and Technology Chattogram.

Email: drtarunroy72@gmail.com

Mobile: +880173188053

2. Dr. Mahmood A Chowdhury Arzu, FCPS, FRCP (Paediatrics) Department of Paediatrics

Chattogram Ma O Shishu Hospital Medical Collage Agrabad, Chattogram.

3. Dr. Wazir Ahmed, FRCP (Paediatrics)

Department of Neonatology

Chattogram Ma O Shishu Hospital Medical Collage Agrabad, Chattogram.

4. Dr. Didarul Alam, FCPS, MD (Paediatrics)

Department of Paediatrics

Chattogram Ma O Shishu Hospital Medical Collage

Agrabad, Chattogram.

5. Dr. Sanjana Islam, MD (Paediatrics)

Associate Professor, Department of Paediatrics

Chattogram Ma O Shishu Hospital Medical Collage Agrabad, Chattogram.

6. Dr. Rabeya Sultana, FCPS(Neonatology)

Regional Roaming Team \& New Born Knowledge Cell (RRT, \& NKC)

Department of Neonatology

Bangabandhu Shaikh Mujib Medical University, Dhaka.

7. Suvendu Ray, BSc (Biochemistry and Biotechnology)

Research Assistant, Genomics Research Center

Chattogram Veterinary and Animal Science University Chattogram.

\section{Introduction:}

Perinatal asphyxia is the most important preventable cause of cerebral injury in the neonatal period leading to very high neonatal mortality and morbidity in developing countries ${ }^{1}$. It occurs mostly during the first and second stage of labor $^{2}$ and is an eventually having far reaching consequences in the neonatal period. It can cause damage to almost every tissue and organ of the body; the most vulnerable ones are central nervous system (72\%), followed by kidneys (42\%), cardiovascular (29\%), gastrointestinal tract $(29 \%)$, and pulmonary $(26 \%)^{3,4,5}$. It results in redistribution of blood flow towards the brain, heart and adrenals and away from kidneys, skin and the gastrointestinal tract to ensure adequate oxygen and substrate deliver to these vital organs ${ }^{6,7}$. Hypoperfusion with concomitant hypercapnia and acidosis contribute to these organ damage ${ }^{8,9}$. As kidneys are very sensitive to oxygen deprivation, renal insufficiency may occur within 24 hours of a hypoxic ischemic episode, which if prolonged, may even lead to irreversible cortical necrosis ${ }^{10}$. So, early recognition of renal failure is important in babies with HIE to facilitate appropriate fluid and electrolyte management as a stable biochemical milieu is vital.

A United Nations Children's Fund (UNICEF) report published on Tuesday said the under-five mortality rate in Bangladesh in 1990 was 144 per 1,000 . But in 2015, the rate is 38 per 1,000 and the child mortality rate across the world was 53 percent, over the same timeframe. About two-third of this high mortality in Bangladesh is due to high perinatal mortality. And perinatal asphyxia constitutes a large portion of perinatal mortality. It is also a leading cause of admission to neonatal care services but in our country, previously no sufficient data is available on incidence of acute renal failure in neonates with perinatal asphyxia and on relationship between low Apgar score ${ }^{10}$ and or the hypoxic ischemic encephalopathy grading 
and development of acute renal failure.

\section{Materials and Methods:}

This Cross-sectional study was conducted in the department of neonatology, Chattogram Maa-Shishu O General Hospital (CMSOGH) from January 2016 to June 2016. All Perinatal asphyxia patients admitted in the department of neonatology, Chattogram Maa-Shishu O General Hospital fulfilling the inclusion criteria were included in the study. Inborn and out born infants with perinatal asphyxia, with postnatal age between 72 - 96 hours were included as cases. Very sick neonates with perinatal asphyxia who required CPR for resuscitation and mechanical ventilation, Newborn with gestational age $<34$ weeks congenital anomalies were excluded from research work. Control was taken from babies of postnatal ward. They all were healthy, kept with mother in postnatal ward and age was between 72 to 96 hours.

\section{- Reference values used in this study:}

Serum Creatinine: Day 3-7: 14 - $86(0.16-1.0 \mathrm{mg} / \mathrm{dl})$

Serum Electrolyte: S. Sodium: 131-144 mmol/L, S. Potassium: $3.2-5.7 \mathrm{mmol} / \mathrm{L}$

Blood Urea: 0.7 - $4.6 \mathrm{mmol} / \mathrm{L}$

\begin{tabular}{lll}
\hline Urinary Indices & Prerenal & Intrinsic Renal \\
\hline Urine osmolality (mosmol/kg water) & $>400$ & $<400$ \\
Urine sodium (mEq/L) & $31 \pm 19$ & $63 \pm 35$ \\
Urine/Plasma creatinine ratio & $29 \pm 16$ & $10 \pm 4$ \\
FeNa (\%) & $<2.5$ & $>2.5$ \\
RFI & $<3.0$ & $>3.0$ \\
\hline
\end{tabular}

Urinary indices in the Neonate used in the evaluation of acute kidney injury

$$
\text { - } \quad \mathrm{FeNa} \%=\frac{\text { Urine } \mathrm{Na} \times \text { Serum } \mathrm{Cr}}{\text { Serum } \mathrm{Na} \times \text { Urine } \mathrm{Cr}} \times 100
$$

To conduct the study ethical clearance was taken from the concerned authority of CMOSH with due procedure. A newborn with history of failure to initiate spontaneous breath immediately after birth and /or history of delayed cry or no cry at all after birth and followed by evidence of Hypoxic Ischemic Encephalopathy (HIE), fulfilling the inclusion and exclusion criteria were considered as case. In this way 150 cases were taken. The cases were categorized according to HIE Sarnat stages. The aim and objectives of the study along with its procedure were explained to the parents in easy, understandable and in local language. Then informed written consent was taken before data collection. Privacy and secrecy were maintained during the procedure. No financial cost was paid by the parents. Detailed history, careful physical examination was performed and case record form was filled in. Two milliliters venous blood was collected from the patient within 72 to 96 hours of age. Adequate amount of urine was also collected from a prefixed sterile plastic bag. Renal status was assessed by doing (1) Serum creatinine, (2) Serum Electrolytes, (3) Urinary electrolytes, (4) Urinary creatinine, (5) Fractional excretion of sodium; Investigations were done in Chattogram Ma-O-Shishu hospital laboratory by auto analyzer. All data were collected in individual structured data collection form Chattogram Ma-O-Shishu hospital. Then results were prepared. Data was analyzed by using SPSS version 15.0 (SPSS Inc. Chicago, USA) statistical software employing appropriate statistical tests like unpaired Student's "t" test, mean, SD, 95\% Confidence limit, Standard error and their "P" values were obtained to see the statistical significance. $\mathrm{P}$ value $<0.05$ was considered as significant.

\section{Results and Observation:}

Table - I: Distribution of the study subjects $(n=180)$.

\begin{tabular}{|c|c|c|}
\hline Study Groups & Frequency & Percentage (\%) \\
\hline Case & 150 & 83.3 \\
\hline Control & 30 & 16.7 \\
\hline Total & 180 & 100.0 \\
\hline \multicolumn{3}{|c|}{ * PNA = Perinatal Asphyxia } \\
\hline Cases & Frequency & Percentage (\%) \\
\hline PNA with HIE stage I & 83 & 55.4 \\
\hline PNA with HIE stage II & 53 & 35.3 \\
\hline PNA with HIE stage III & 14 & 9.3 \\
\hline Total & 150 & 100.0 \\
\hline
\end{tabular}

* PNA $=$ Perinatal Asphyxia

Table - II: Statistics of plasma creatinine among the study subjects $(\mathrm{n}=180)$.

\begin{tabular}{|c|c|c|c|c|c|c|}
\hline Plasma Creatinine (mg/dl) & $\mathrm{N}$ & Mean & $\pm \mathrm{SD}$ & Median & Range & P value* \\
\hline $\begin{array}{l}\text { Case } \\
\text { (Newborn with PNA) }\end{array}$ & 150 & 1.64 & 0.33 & 1.62 & $0.50-2.90$ & $\begin{array}{c}\mathrm{P}<0.001 \\
\text { Highly }\end{array}$ \\
\hline Control & 30 & 0.41 & 0.09 & 0.39 & $0.21-0.61$ & Significant \\
\hline Total & 180 & 1.43 & 0.55 & 1.56 & $0.21-2.90$ & $*$ t-test \\
\hline
\end{tabular}

* PNA $=$ Perinatal Asphyxia

The mean value of $\mathrm{S}$. Creatinine of case and control are $1.64 \mathrm{mg} / \mathrm{dl}$ and $0.41 \mathrm{mg} / \mathrm{dl}$ respectively which is statistically significant $(\mathrm{P}<0.001)$.

Table - III: Plasma creatinine among the case (with t-test and ANOVA significance) $(\mathrm{n}=150)$.

\begin{tabular}{lcccc}
\hline \multirow{2}{*}{ P. Creatinine } & \multicolumn{3}{c}{ Stages } & \multirow{2}{*}{ p value* } \\
\cline { 2 - 4 } Normal & Stage I & Stage II & Stage III & \\
\hline Abnormal & $49(59.0)$ & $27(50.9)$ & $6(42.9)$ & \multirow{2}{*}{0.422} \\
\hline Total & $34(41.0)$ & $26(49.1)$ & $8(57.1)$ & \\
\hline
\end{tabular}

*Chi square test was done to measure the level of significance. Figure within parentheses indicates in percentage

\begin{tabular}{lcccccc}
\hline \multicolumn{1}{c}{ Plasma Creatinine (mg/dl) } & $\mathrm{N}$ & Mean & $\pm \mathrm{SD}$ & Median & Range & P value $^{*}$ \\
\hline PNA stage 1 & 83 & 1.13 & 0.28 & 1.14 & $0.50-1.6$ & $\mathrm{P}<0.001$ \\
PNA stage 2 & 53 & 1.47 & 0.37 & 1.38 & $0.90-2.10$ & Highly \\
PNA stage 3 & 14 & 1.85 & 0.20 & 1.72 & $1.50-2.90$ & Significant \\
Total & 150 & 1.64 & 0.33 & 1.62 & $0.50-2.90$ & $*$ ANOVA \\
\hline \multicolumn{6}{c}{ * PNA = Perinatal Asphyxia }
\end{tabular}

Among the case, normal value and abnormal value of $\mathrm{S}$. creatinine in HIE stage I, stage II and stage III are not statistically significant. But the mean value of the cases of HIE stage $I$ is $1.13 \pm 0.28 \mathrm{mg} / \mathrm{dl}$, stage II is $1.14 \pm 0.37 \mathrm{mg} / \mathrm{dl}$ and in stage III is $1.84 \pm 0.20 \mathrm{mg} / \mathrm{dl}$, that is significant. 
Table-IV: Statistics of FeNa among the study subjects $(\mathrm{n}=180)$.

\begin{tabular}{|c|c|c|c|c|c|c|}
\hline $\mathrm{FeNa}(\%)$ & $\mathrm{N}$ & Mean & $\pm \mathrm{SD}$ & Median & Range & $P$ value* \\
\hline $\begin{array}{l}\text { Case } \\
\text { (Newborn with PNA) }\end{array}$ & 150 & 2.44 & 0.55 & 2.49 & $1.11-4.31$ & $\begin{array}{c}\mathrm{P}<0.001 \\
\text { Highly }\end{array}$ \\
\hline Control & 30 & 1.06 & 0.38 & 1.04 & $0.51-1.77$ & Significant \\
\hline TOTAL & 180 & 2.21 & 0.73 & 2.40 & $0.51-4.31$ & $* \mathrm{t}$-test \\
\hline
\end{tabular}

$*$ PNA $=$ Perinatal Asphyxia $; \mathrm{FeNa}=$ Fractionated Excretion of Sodium

This table shows the mean value of Fractional Excretion of Sodium (FeNa) in case is 2.44 and in control is 1.06 which is statistically significant ( $\mathrm{P}$ value is $<0.001$ ).

Table -V: Distribution of FeNa by stages (with t-test and ANOVA significance).

\begin{tabular}{lcccc}
\hline \multirow{2}{*}{ FeNa } & \multicolumn{3}{c}{ Stages } & \multirow{2}{*}{ p value* } \\
\cline { 2 - 4 } & Stage I & Stage II & Stage III & \\
\hline Normal & $57(68.7)$ & $22(41.5)$ & $1(7.1)$ & \multirow{2}{*}{0.001} \\
Abnormal & $26(31.3)$ & $31(58.5)$ & $13(92.9)$ & \\
\hline Total & $83(100.0)$ & $53(100.0)$ & $14(100.0)$ & \\
\hline
\end{tabular}

*Chi square test was done to measure the level of significance. Figure within parentheses indicates in percentage.

\begin{tabular}{lcccccc}
\hline \multicolumn{1}{c}{ FeNa (\%) } & $\mathrm{N}$ & Mean & $\pm \mathrm{SD}$ & Median & Range & P value* \\
\hline PNA stage 1 & 83 & 2.25 & 0.52 & 2.39 & $1.11-3.74$ & $\mathrm{P}<0.001$ \\
PNA stage 2 & 53 & 2.65 & 0.55 & 2.62 & $1.38-4.31$ & Highly \\
PNA stage 3 & 14 & 2.72 & 0.22 & 2.73 & $2.24-3.12$ & Significant \\
Total & 150 & 2.44 & 0.55 & 2.49 & $1.11-4.31$ & *ANOVA \\
\hline
\end{tabular}

* PNA $=$ Perinatal Asphyxia $; \mathrm{FeNa}=$ Fractionated Excretion of Sodium

This table shows normal and abnormal values of FeNa in stage I; stage II and stage III are significant statistically and their mean values are also statistically significant.

\section{Discussion:}

Perinatal asphyxia is one of the important causes of neonatal morbidity and mortality in Bangladesh (BDSH 2005). The kidneys are the commonest organs to be involved in perinatal asphyxia and it is very sensitive to ischemic damage (Aurora and Snyder 2004 \& Talos 1996). So, the renal function assessment in perinatal asphyxia is essential for accurate management of metabolic derangement particularly fluid, electrolytes and acid base imbalance resulting from renal function impairment. For early prediction of renal injury, markers of renal injury (i, e. S. Electrolytes, S. Creatinine, FeNa, and RFI) are more sensitive and specific in the determination of indices of renal function (Willis et al. 1997).

Traditionally, assessment of perinatal asphyxia has relied on a combination of clinical observations such as Apgar score and measurement of serum creatinine level. There was weakness in such methods because Apgar score may be influenced by metabolic and chromosomal disorders other than perinatal asphyxia. So, determination of more sensitive and specific markers of renal tubular dysfunction of renal injury in perinatal asphyxia (Willis et al. 1997) is essential. In this study 180 neonates were enrolled; among them 150 patients were cases and 30 patients were control. Among the cases, on the basis of clinical status, 83 (55\%) neonates were assigned as HIE stage I, 53 (35\%) neonates were assigned as HIE stage II and 14 (9\%) neonates were assigned as HIE III.

Among the cases, numbers of male newborns were higher than female newborns. Presenting features coma, convulsion and hyper alert were predominant features in HIE stage III, stage II and stage I respectively. In this study it was found that perinatal asphyxia is more common in male sex than female sex $(53 \%$ Vs $47 \%)$, People of rural area than urban $(62.7 \%$ Vs $37.3 \%)$, Home delivery than hospital delivery (58\% Vs 42\%) and NVD than LUCS (65.3 Vs 34.7). The high incidence of PNA in hospital delivery and by LUCS is because from rural area mothers came to the hospital with complication and emergency delivery was done by LUCS to save mother's life and to secure the baby.

In my study among 150 cases 55\% were HIE stage I, 35\% were HIE stage II and $9 \%$ were HIE stage III. It is near to the findings done by D Saha, MAH Hollah, S Afroz, M Banerjee, TH Khan and CK Saha in Dhaka Medical College in January 2012 to January 2013, where among 102 cases $30.4 \%$ had mild asphyxia, $48 \%$ moderate and $21.6 \%$ had severe asphyxia. In my study, the discrepancy is higher percentage of stage I is most possible due to higher incidence of PNA in rural areas of the country and also difference in admission protocol of PNA patients in different institutions. In my study, in HIE stage I, among 83 patients $49(59 \%)$ patients have normal S. creatinine and 34 (41\%) patients have abnormally high S. creatinine. Whereas, in stage II, among 53 patients $27(50.9 \%)$ patients have normal S. creatinine and $26(49.1 \%)$ patients have abnormally high S. creatinine and in stage III, among 14 patients $6(42.9 \%)$ patients have normal S. creatinine and $8(57.1 \%)$ patients have abnormally high S. creatinine. Mean value of $\mathrm{S}$. creatinine in all stages is $1.64 \pm 0.33 \mathrm{mg} / \mathrm{dl}$. This value is consistent with Dr. Khalilur Rahaman study of Dhaka Shishu hospital 2007, where Serum creatinine values were significantly higher in asphyxiated neonates as compared to the control group. It is also consistent with Girish Gopal) and Group II at all, $(\mathrm{p}=0.0001)$.

In this study in stage I, 57 (68.7\%) baby has normal FeNa and $26(31.3 \%)$ baby has abnormally high FeNa. For stage II, $22(41.5 \%)$ baby has normal FeNa and 31 (58.5\%) baby has abnormally high FeNa and for stage III, only 1 (7.1\%) baby has normal FeNa and $13(92.9 \%)$ baby has abnormally high FeNa. There $\mathrm{P}$ value is 0.001 , which is statistically highly significant.

Tubular dysfunction was confirmed by the fractional excretion of sodium, which was grossly abnormal in group 1 (mean $319 \%$ ) mildly increased in group $2(1-7 \%)$, and normal in group $3(0-3 \%)$. That in control infants was below $1 \%$ and in sodium balance studies the fractional excretion of sodium in healthy infants of similar gestational age with a sodium intake of $2-5 \mathrm{mmol} / \mathrm{kg} /$ day has been reported to be normally less than 1\%. 17 (Prediction of acute renal failure after birth asphyxia D S Roberts, G B Haycock, R N Dalton, C Turner, P Tomlinson, L Stimmler, J W Scopes). 
In my study, In stage I, Mean $\pm \mathrm{SD}$ of FeNa value is $2.25 \pm$ 0.52 , for Stage II, Mean $\pm \mathrm{SD}$ value of $\mathrm{FeNa}$ is $2.65 \pm 0.55$ and for stage III, Mean \pm SD of FeNa value is $2.72 \pm 0.22$ and "p" value 0.001 which is statistically highly significant. FeNa levels were higher in neonates with HIE II and III than in the control group while it was comparable in babies of HIE $\mathrm{O}$ and I stage with that of control babies. (Renal Failure in Asphyxiated Neonates B.D. Gupta, Pramod Sharma, Jyoti Bagla, Manish Parakh and J.P. Soni).

The high values of the FeNa signify that this AKI is intrinsic in nature.

\section{Conclusion:}

To evaluate the renal function impairment in asphyxiated infant some investigations are usually done. These are S. creatinine, S. electrolytes. But to see the extent of injury we need to do some additional investigations like Fractional excretion of sodium (FeNa). It is useful to find out specific AKI to get better outcome.

\section{Conflict of Interest: None.}

\section{Acknowledgement:}

It is a great pleasure on my part to express the best regards and gratefulness to the Department of Paediatrics, Chattogram Maa O Shishu Medical College and Hospital, Agrabad, Chattogram for completion of this research. I express my indebtedness to all my patients - living and dead, their parents who contributed in no small way to this research, but for whom this entire exercise would have been unimaginable.

\section{References:}

1. Shireen N, Nahar N, Mollah AH. Risk Factors and Short-Term Outcome of Birth Asphyxiated Babies in Dhaka Medical College Hospital. Bangladesh J Child Heal. 1970; 33(3 SE-Original Articles).

https://doi.org/10.3329/bjch.v33i3.5688
2. Roberts G. Manual of Neonatal Care. 1987; 15. https://doi.org/10.1016/0378-3782(87)90024-7

3. Gomella TL, Cunningham MD, Eyal FG, Tuttle DJ. Neonatology: management, procedures, on-call problems, diseases and drugs. 2013.

4. Shah P, Riphagen S, Beyene J, Perlman M. Multiorgan dysfunction in infants with post-asphyxial hypoxic-ischaemic encephalopathy. Arch Dis Childhood-Fetal Neonatal Ed. 2004; 89(2): F152-F155.

https://doi.org/10.1136/adc.2002.023093

PMid:14977901 PMCid:PMC1756028

5. Martín-Ancel A, García-Alix A, Cabañas FGF, Burgueros M, Quero J. Multiple organ involvement in perinatal asphyxia. J Pediatr. 1995; 127(5): 786-793.

https://doi.org/10.1016/S0022-3476(95)70174-5

6. Kliegmassn RM, Stanton B, Geme JS, Schor NF, Behrman RE. Nelson textbook of pediatrics. 2015.

7. Covey M V, Levison SW. Pathophysiology of perinatal hypoxia-ischemia and the prospects for repair from endogenous and exogenous stem cells. Neoreviews. 2006; 7(7): e353-e362. https://doi.org/10.1542/neo.7-7-e353

8. McIntosh N, Helms P, Smyth R, Logan S. Forfar and Arneil's Textbook of Paediatics. Churchill Livingstone; 2008.

9. Perlman JM, Tack ED, Martin T, Shackelford G, Amon E. Acute systemic organ injury in term infants after asphyxia. Am J Dis Child. 1989; 143(5): 617-620.

https://doi.org/10.1097/00132582-198910000-00022

https://doi.org/10.1001/archpedi.1989.02150170119037

PMid:2718998

10. Apgar V. A proposal for a new method of evaluation of the newborn. Class Pap Crit Care. 1952; 32(449): 97. 